\title{
PARAMETERS AFFECTING LYCOPENE EXTRACTION FROM TOMATO POWDER AND ITS ANTIOXIDANT ACTIVITY
}

\author{
Mehmet ÜSTÜNDAŞ ${ }^{1}$, H. Banu YENER ${ }^{1}$, Şerife Ş. HELVACI ${ }^{1, *}$ \\ ${ }^{1}$ Department of Chemical Engineering, Faculty of Engineering, Ege University, 35100, Bornova, İzmir, Turkey
}

\begin{abstract}
The extraction of lycopene from dried tomato powder was carried out using ultrasound assisted (UAE) and conventional solvent (COSE) extraction methods with varying liquid/solid ratio (10:1-50:1), extraction time (5-60 min), temperature $\left(20-50^{\circ} \mathrm{C}\right)$ and ultrasonic power $(150-200 \mathrm{~W})$. The response surface methodology was used to optimize the extraction parameters and to determine their individual and interaction effects on the extraction yield. The maximum extraction yields of UAE (722.321 mg lycopene/kg tomato powder) and COSE (975.833 mg lycopene/kg tomato powder) was observed using the following conditions: $166 \mathrm{~W}$ for 26 $\mathrm{min}$, and a 56:1 liquid/solid ratio, and $45^{\circ} \mathrm{C}$ for $50 \mathrm{~min}$, and a 56:1 liquid/ solid ratio, respectively. At the same extraction conditions $\mathrm{UAE}$ is reaching the same extraction yield faster than the COSE. Even the lycopene contents of the extracts were the same, the antioxidant capacity of the UAE and COSE extracts were 12.48 and $11.08 \mathrm{mg}$ Trolox/g tomato powder, respectively.
\end{abstract}

Keywords: Lycopene, Tomato powder, Ultrasound assisted extraction, Response surface methodology, Antioxidant capacity

\section{INTRODUCTION}

Vegetables and fruits have been used for the treatment of many diseases for decades. Nowadays, there is an increased attention towards plants, which have active ingredients with therapeutic effects. Since these active ingredients such as lycopene, curcumin and resveratrol can be extracted from the vegetables and fruits, their applications are growing in the pharmaceutical, cosmetic and food industries.

Lycopene, a common carotenoid, has been recognized as a potential bioactive natural compound found in fruits and vegetables such as tomatoes [1,2], apricot [3], red grapefruit [4, 5], cherry [6], pink guava [7], papaya [8], peaches [6] and watermelon [9, 10], and is responsible for their red color. The lycopene content of fruits and vegetables can vary according to the plant type, growing conditions, and agricultural techniques [11]. Lycopene has unique structural and chemical features that may contribute to specific biological properties due to its conjugated double bonds [1]. These double bonds are responsible for its biological properties such as antioxidant activity and a tendency to oxidative degradation [12]. As an antioxidant agent, the species contain reactive oxygen, singlet molecular oxygen $\left({ }^{1} \mathrm{O}_{2}\right)$, and superoxide radical anion $\left(\mathrm{O}^{2-}\right)$, which can be trapped by the lycopene. This ability reduces the damage caused by free radicals which have a tendency to oxidize the lipids, proteins, and DNA [13,14]. Epidemiological studies have showed that consumption of lycopene rich foods are reducing the risk of prostate cancer [15], cardiovascular disease [16], and diseases affecting the skin and the eye [17].

Lycopene from tomato is conventionally extracted using the solvent extraction (COSE) method. The solvent extraction has some disadvantages such as a long extraction time with low efficiency. Therefore, some novel methods were developed for the extraction of lycopene such as supercritical fluid extraction (SFE) $[18,19]$, microwave assisted extraction (MAE) [20], and ultrasonic assisted extraction (UAE) [2, $4,8,21,22]$. Among these methods, SFE and MAE require high energy consumption and expensive equipment whereas UAE is a promising and commercially applicable extraction method with less

*Corresponding Author: serife.seref.helvaci@ege.edu.tr

Receiving Date: 23 October 2017 Publishing Date: 29 June 2018 
extraction time and low cost for equipment. Besides the methods, the extraction parameters such as extraction time, liquid/solid ratio, temperature, and ultrasonic power are also effective on the lycopene yield. Therefore, it is important to determine the suitable extraction method and optimum extraction conditions for high lycopene yield and antioxidant activity with low cost.

In the present study, the UAE and COSE methods were used to extract lycopene from tomato powder obtained by drying fresh tomatoes. The effects of the different parameters such as extraction time, liquid/solid ratio, temperature, and ultrasonic power, on the yield of the lycopene extraction were investigated. The experimental design was accomplished using the central composite design (CCD). The effects of the parameters and their interactions on the extraction yield were determined using response surface methodology (RSM). The optimum parameters for both the UAE and COSE methods were determined by considering the highest lycopene yield and minimum lycopene degradation. The effectiveness of the UAE and COSE methods was compared in terms of both lycopene yield and antioxidant capacity.

\section{MATERIALS AND METHODS}

\subsection{Materials}

Fresh tomatoes cultivated in Antalya (Turkey) were used as the lycopene source and its moisture content was found to be $95 \%$ (by wt). The fresh tomatoes were cut into two pieces and then dried in an oven for $48 \mathrm{~h}$. The drying temperature was selected as $60^{\circ} \mathrm{C}$ [23]. The dried tomato pieces were grinded to obtain tomato powder (TP). The particle size of the TP was determined by screen analysis and found to be in the range of 100 to $300 \mu \mathrm{m}$. The analytical grade of the organic solvents n-hexane, acetone, ethanol, and tetrahydrofuran (THF) were purchased from Merck (Merck, Darmstadt, Germany). The HPLC grade ( $\geq 99.0 \%$ in purity) of 2, 2-azinobis (3-ethylbenzothiazoline-6-sulfonic acid) ammonium salt (ABTS), used as a radical scavenging agent was purchased from Fluka (Fluka, Deisenhofen, Germany). The potassium peroxodisulphate and $( \pm)-6$-Hydroxy-2, 5, 7, 8-tetramethylchromane-2-carboxylic acid (Trolox) were purchased from Sigma-Aldrich (Sigma, St. Louis, MO, USA).

\subsection{Ultrasonic Assisted Extraction (UAE) Method}

The extraction by ultrasonic power was carried out in a home-made jacketed borosilicate glass reactor using an ultrasonic probe system (Model VCX-750, $24 \mathrm{kHz}$, Sonics \& Materials Inc., USA) with exclusion of light. A condenser was equipped to the reactor in order to eliminate the loss of solvent caused by the evaporation. The experimental setup is given in Figure 1. The maximum output power of the ultrasonic probe is $750 \mathrm{~W}$ and the amplitude in the experiments was changed in order to obtain the power investigated. A solvent mixture of $30 \mathrm{ml}$ of hexane : acetone : ethanol $(2: 1: 1)$ by volume [10] was added to the TP in the glass reactor. Although $n$-hexane is a suitable solvent for the lycopene, a solvent mixture was used due to the positive synergistic interaction of $n$-hexane with ethanol and acetone on the extraction of lycopene $[1,24]$. The ultrasonic probe was immersed into the reactor operating at a constant stirring rate of $500 \mathrm{rpm}$ to prevent precipitation of the TP. Increase in the temperature of the extraction medium caused by the long period of ultrasonication was minimized by circulating cooling water in the jacket of the reactor. The temperature was kept nearly constant at $20 \pm 5^{\circ} \mathrm{C}$ and was measured with the help of a thermocouple immersed inside of the glass reactor during the extraction period. After the extraction process, the reactor was taken out and waited for the settling of the tomato powder. $1.5 \mathrm{ml}$ of cold water was added to $5 \mathrm{ml}$ of supernatant to separate the polar and non-polar layers. The lycopene rich non-polar n-hexane phase was used to determine the amount of lycopene extracted. 


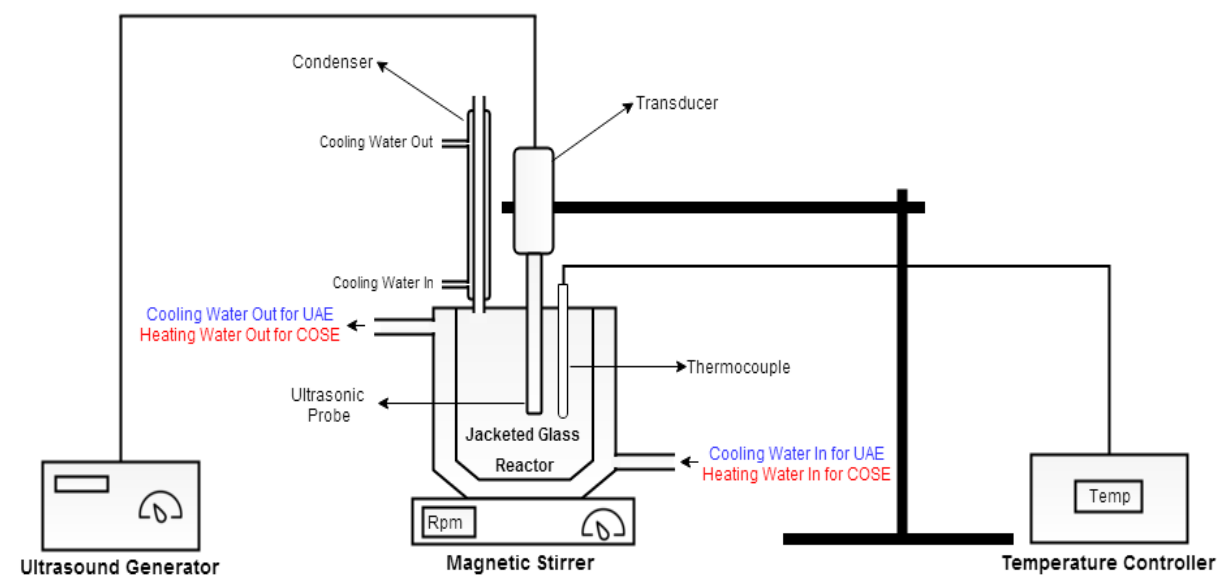

Figure 1. Schematic representation of experimental setup of UAE and COSE.

\subsection{Conventional Organic Solvent Extraction (COSE) Method}

In COSE, exactly the same experimental procedure as described in UAE method in Section 2 and experimental set-up given in Figure 1 were used without the use of the ultrasonic probe. Although, the UAE experiments were performed at a constant temperature of $20 \pm 5^{\circ} \mathrm{C}$, temperature was selected as an extraction parameter in the COSE method. The criteria used in the determination of the extraction temperature are the boiling point of the solvents used and the undesirable reactions causing in the degradation of lycopene. In COSE, the temperature investigated was adjusted by circulating water in the jacket of the reactor whereas the same jacket was used for the cooling of the extraction medium in UAE.

\subsection{Determination of Lycopene}

The total lycopene content of the samples in the non-polar n-hexane phase was measured using a UVVisible spectrophotometer (Schimadzu 2600, Kyoto, Japan) at its characteristic wavelength of $503 \mathrm{~nm}$. An extinction coefficient of $17.2 \times 10^{4} \mathrm{M}^{-1} \mathrm{~cm}^{-1}$ was used for the determination of the lycopene amount $[25,26]$. The UV-visible spectrum of the TP extract in the n-hexane is given in Figure 2 and the chemical structure of all-trans lycopene as an inset in Figure 2.

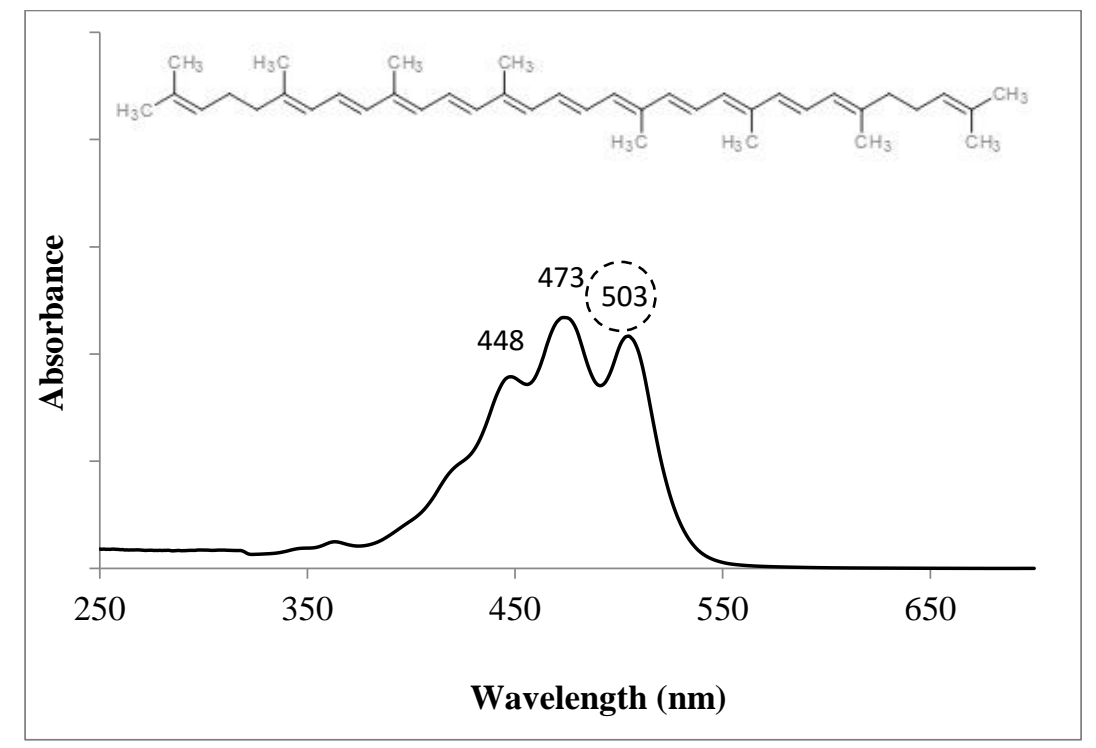

Figure 2. UV-visible spectrum of the TP extract in the n-hexane and chemical structure of all-trans lycopene (inset). 
The lycopene yield, $Y$ was defined by Eq. (1) as

$$
Y=\frac{\text { amount of lycopene extracted }(\mathrm{mg})}{\text { initial amount of } T P(\mathrm{~kg})}
$$

\subsection{Experimental Design of UAE and COSE}

The experiments were designed using the CCD method with three factors, three levels and one response variable, the lycopene yield. The lower and upper levels of the factors were determined based on the preliminary studies (Table 1). The experimental designs of each extraction type consisted of 20 random experiments with six replicates at the center points. In addition to the replicates at the center points, all experiments were triplicated. The experimental conditions and the corresponding average lycopene yields obtained in UAE and COSE are summarized in Table 2 and Table 3, respectively.

Table 1. Independent variables and their levels in the UAE and COSE experiments.

\begin{tabular}{lcccccc}
\hline & \multicolumn{7}{c}{ Variables of UAE } \\
\hline \multirow{2}{*}{ Un-coded } & \multirow{2}{*}{ Coded } & \multicolumn{7}{c}{ Levels } \\
\cline { 3 - 7 } & $X_{1}$ & -1.3 & -1 & 0 & 1 & 1.3 \\
\hline Extraction time (min) & $X_{2}$ & 142.5 & 150.0 & 175.0 & 200.0 & 28.0 \\
Ultrasonic power (W) & $X_{3}$ & 4.0 & 10.0 & 30.0 & 50.0 & 56.0 \\
Liquid/solid ratio (v/w) & \multicolumn{7}{c}{ Variables of COSE } \\
\hline & \multirow{2}{*}{ Coded } & -1.3 & -1 & 0 & 1 \\
\hline \multirow{2}{*}{ Un-coded } & $X_{1}$ & 2.5 & 10.0 & 35.0 & 60.0 & 67.5 \\
& $X_{2}$ & 15.5 & 20.0 & 35.0 & 50.0 & 54.5 \\
Extraction time $(\mathrm{min})$ & $X_{3}$ & 4.0 & 10.0 & 30.0 & 50.0 & 56.0 \\
Temperature $\left({ }^{\circ} \mathrm{C}\right)$ & & & & & & \\
Liquid/solid ratio $(\mathrm{v} / \mathrm{w})$ & & &
\end{tabular}

The experimental data was evaluated using RSM for the optimization of the parameters and model prediction. The data fitted to the second-order polynomial model given in Eq. (2) with the appropriate factors.

$$
Y=\beta_{0}+\sum \beta_{i} X_{i}+\sum \beta_{i i} X_{i}^{2}+\sum \sum \beta_{i j} X_{i} X_{j}
$$

where $\beta_{0}$ is the value of the fixed responses at the central point of the experiment; $\beta_{i}, \beta_{i i}$, and $\beta_{j j}$ are the linear-, the quadratic-, and the interaction-regression coefficients of the model, respectively. $X_{i}$ and $X_{j}$ are the coded variables. The optimum extraction conditions were determined considering the maximum lycopene yield.

\subsection{Statistical Analysis}

The significances of the parameters on the lycopene yield were determined using the Analysis of Variance (ANOVA) with a confidence level of 95\% (Minitab software, Trial version, Inc., State College, PA, U.S.A.). 
Üstündaş et al. / Anadolu Univ. J. of Sci. and Technology A-Appl. Sci. and Eng. 19 (2) - 2018

Table 2. Central composite design of the UAE

\begin{tabular}{|c|c|c|c|c|c|c|c|}
\hline Runs & $X_{1}$ & $X_{2}$ & $X_{3}$ & Extraction time (min) & $\begin{array}{l}\text { Ultrasonic } \\
\text { power (W) }\end{array}$ & $\begin{array}{l}\text { Liquid/solid ratio } \\
\text { (v/w) }\end{array}$ & $\begin{array}{c}\text { Yield }^{*}, Y \\
\text { (mg lycopene/kg TP) }\end{array}$ \\
\hline 1 & 0 & 0 & 0 & 15.0 & 175.0 & 30.0 & $689.447 \pm 1.69$ \\
\hline 2 & 0 & 0 & 1.3 & 15.0 & 175.0 & 56.0 & $696.935 \pm 1.96$ \\
\hline 3 & -1 & -1 & 1 & 5.0 & 150.0 & 50.0 & $576.863 \pm 3.10$ \\
\hline 4 & 0 & -1.3 & 0 & 15.0 & 142.5 & 30.0 & $624.523 \pm 3.10$ \\
\hline 5 & -1 & 1 & 1 & 5.0 & 200.0 & 50.0 & $610.880 \pm 1.79$ \\
\hline 6 & 0 & 0 & 0 & 15.0 & 175.0 & 30.0 & $659.447 \pm 1.47$ \\
\hline 7 & 1 & 1 & 1 & 25.0 & 200.0 & 50.0 & $697.607 \pm 0.38$ \\
\hline 8 & -1 & 1 & -1 & 5.0 & 200.0 & 10.0 & $540.625 \pm 3.18$ \\
\hline 9 & 0 & 0 & 0 & 15.0 & 175.0 & 30.0 & $669.447 \pm 0.53$ \\
\hline 10 & -1.3 & 0 & 0 & 2.0 & 175.0 & 30.0 & $583.260 \pm 3.00$ \\
\hline 11 & 0 & 0 & 0 & 15.0 & 175.0 & 30.0 & $649.147 \pm 7.60$ \\
\hline 12 & 0 & 0 & 0 & 15.0 & 175.0 & 30.0 & $639.427 \pm 3.58$ \\
\hline 13 & 0 & 0 & 0 & 15.0 & 175.0 & 30.0 & $679.447 \pm 2.67$ \\
\hline 14 & 0 & 0 & -1.3 & 15.0 & 175.0 & 4.0 & $533.434 \pm 5.81$ \\
\hline 15 & 1 & -1 & 1 & 25.0 & 150.0 & 50.0 & $710.538 \pm 7.61$ \\
\hline 16 & -1 & -1 & -1 & 5.0 & 150.0 & 10.0 & $485.113 \pm 6.02$ \\
\hline 17 & 1 & -1 & -1 & 25.0 & 150.0 & 10.0 & $581.561 \pm 2.34$ \\
\hline 18 & 1.3 & 0 & 0 & 28.0 & 175.0 & 30.0 & $645.323 \pm 0.33$ \\
\hline 19 & 0 & 1.3 & 0 & 15.0 & 207.5 & 30.0 & $635.200 \pm 4.74$ \\
\hline 20 & 1 & 1 & -1 & 25.0 & 200.0 & 10.0 & $600.124 \pm 2.54$ \\
\hline
\end{tabular}

*Mean value of the experimentally obtained yield of lycopene \pm standard deviation (number of replicates $=3$ ).

Table 3. Central composite design of the COSE

\begin{tabular}{|c|c|c|c|c|c|c|c|}
\hline Runs & $X_{I}$ & $X_{2}$ & $X_{3}$ & Extraction time (min) & $\begin{array}{c}\text { Temperature } \\
\left({ }^{\circ} \mathrm{C}\right)\end{array}$ & $\begin{array}{c}\text { Liquid/solid ratio } \\
(\mathrm{v} / \mathrm{w})\end{array}$ & $\begin{array}{c}\text { Yield }^{*}, Y \\
\text { (mg lycopene/kg TP) }\end{array}$ \\
\hline 1 & -1 & 1 & -1 & 10.0 & 50.0 & 10.0 & $640.769 \pm 0.42$ \\
\hline 2 & 0 & 0 & 0 & 35.0 & 35.0 & 30.0 & $900.664 \pm 0.57$ \\
\hline 3 & 0 & 0 & 0 & 35.0 & 35.0 & 30.0 & $870.585 \pm 1.14$ \\
\hline 4 & 1 & -1 & -1 & 60.0 & 20.0 & 10.0 & $741.513 \pm 1.86$ \\
\hline 5 & 1 & 1 & 1 & 60.0 & 50.0 & 50.0 & $975.456 \pm 1.33$ \\
\hline 6 & -1 & -1 & 1 & 10.0 & 20.0 & 50.0 & $635.785 \pm 2.62$ \\
\hline 7 & 0 & 1.3 & 0 & 35.0 & 54.5 & 30.0 & $800.741 \pm 2.83$ \\
\hline 8 & 0 & 0 & 0 & 35.0 & 35.0 & 30.0 & $860.300 \pm 0.94$ \\
\hline 9 & -1.3 & 0 & 0 & 2.5 & 35.0 & 30.0 & $500.653 \pm 1.45$ \\
\hline 10 & 0 & -1.3 & 0 & 35.0 & 15.5 & 30.0 & $700.463 \pm 1.19$ \\
\hline 11 & 0 & 0 & 1.3 & 35.0 & 35.0 & 56.0 & $856.895 \pm 1.08$ \\
\hline 12 & 0 & 0 & -1.3 & 35.0 & 35.0 & 4.0 & $635.450 \pm 3.49$ \\
\hline 13 & 0 & 0 & 0 & 35.0 & 35.0 & 30.0 & $888.350 \pm 0.76$ \\
\hline 14 & 1.3 & 0 & 0 & 67.5 & 35.0 & 30.0 & $835.687 \pm 2.02$ \\
\hline 15 & 1 & -1 & 1 & 60.0 & 20.0 & 50.0 & $918.125 \pm 1.00$ \\
\hline 16 & -1 & -1 & -1 & 10.0 & 20.0 & 10.0 & $475.522 \pm 1.13$ \\
\hline 17 & 0 & 0 & 0 & 35.0 & 35.0 & 30.0 & $895.452 \pm 0.50$ \\
\hline 18 & 0 & 0 & 0 & 35.0 & 35.0 & 30.0 & $853.575 \pm 1.13$ \\
\hline 19 & -1 & 1 & 1 & 10.0 & 50.0 & 50.0 & $823.452 \pm 0.83$ \\
\hline 20 & 1 & 1 & -1 & 60.0 & 50.0 & 10.0 & $771.412 \pm 3.24$ \\
\hline
\end{tabular}

*Mean value of the experimentally obtained yield of lycopene \pm standard deviation (number of replicates $=3$ ).

\subsection{Determination of Antioxidant Activity of TP}

The antioxidant activity of TP was determined using the ABTS radical scavenging method and Trolox was used as a reference antioxidant material $[27,28]$. The ABTS radical scavenging method is illustrated in Figure 3. The solvent mixture in the extract prepared was evaporated using a rotary evaporator. The residue was dissolved in THF and used for the preparation of sample solutions at different concentrations on the basis of the dry TP. In order to analyze the antioxidant capacity of TP, the stock solution of the radical cation, $\mathrm{ABTS}^{+}$, was prepared with the addition of $10 \mathrm{ml}$ of $7 \mathrm{mM}$ aqueous $\mathrm{ABTS}$ solution to 10 $\mathrm{ml}$ of $2.45 \mathrm{mM}$ aqueous potassium peroxydisulphate solution. The mixture was kept at room temperature in the dark for 24 hours in order to obtain a stable solution of ABTS ${ }^{+}$. The stock solution 
of $\mathrm{ABTS}^{+}{ }^{+}$was diluted with ethanol to obtain a working solution with an absorbance of $0.7 \pm 0.01$ at 734 $\mathrm{nm}$. The aqueous Trolox solutions were prepared with the appropriate concentrations.

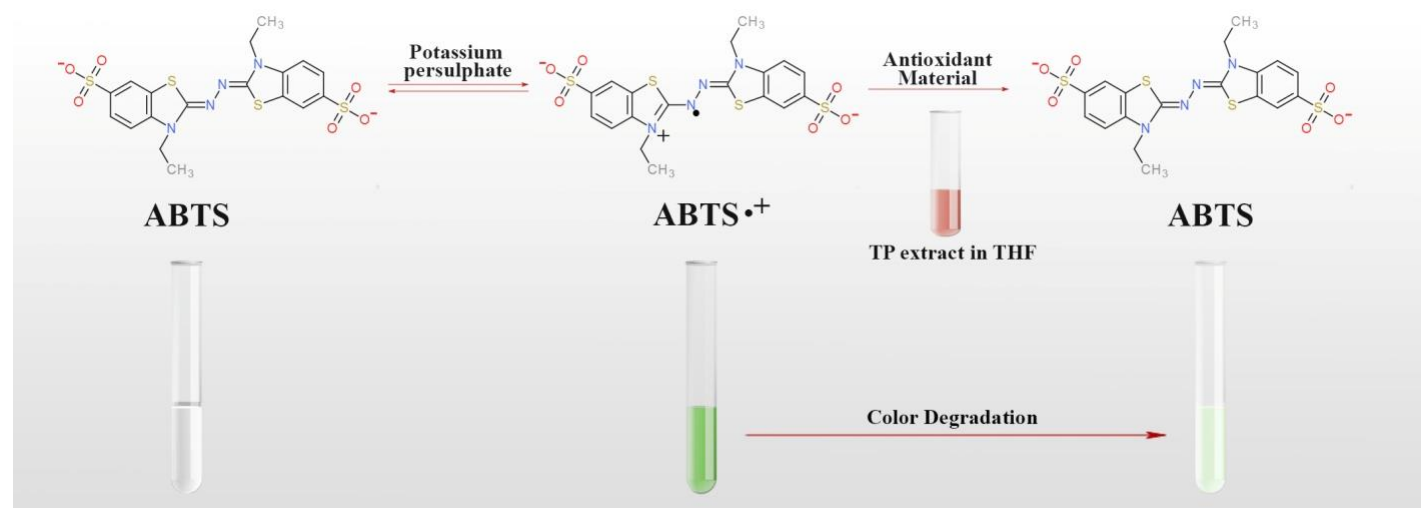

Figure 3. Schematic representation of the ABTS radical scavenging method

To determine the antioxidant capacity, $0.2 \mathrm{ml}$ of the sample solution or reference solution (Trolox) was added to $2 \mathrm{ml}$ of the working solution and let to stand for $30 \mathrm{~min}$ for the completion of the reaction. A control solution was prepared with the addition of $0.2 \mathrm{ml}$ of pure THF to the $2 \mathrm{ml}$ of working solution. At the end of the reaction, both for the sample or reference solution and control solution, the absorbance of the $\mathrm{ABTS}^{++}$was measured at $734 \mathrm{~nm}$. The percentage inhibition of the $\mathrm{ABTS}^{++}$, was calculated using Eq.(3).

$$
\text { Inhibition of } \mathrm{ABTS}^{+}, \%=\frac{A_{\text {Control }}-A_{\text {Sample or Reference }}}{A_{\text {Control }}} \times 100
$$

where $A_{\text {Control }}$ and $A_{\text {Sample or Reference }}$ are the absorbance's of the ABTS.+ in the control solution and sample or reference solution, respectively. The antioxidant capacities were calculated on the basis of calibration curves plotted using different concentrations of the sample and reference solution.

\section{RESULTS AND DISCUSSION}

\subsection{UAE Method}

The ultrasonic assisted extractions were performed based on the three factors experimental design, $X_{1}$ (extraction time, $\mathrm{min}$ ), $X_{2}$ (ultrasonic power, $\mathrm{W}$ ), and $X_{3}$ (liquid/solid ratio, v/w). The results showed that the lycopene yield changes between 485 and $711 \mathrm{mg}$ lycopene $/ \mathrm{kg} \mathrm{TP}$ and from 24 to $36 \mathrm{mg}$ lycopene $/ \mathrm{kg}$ of fresh tomatoes depending on the parameters. A quadratic polynomial regression model was used to define the relations between the parameters $\left(X_{i}\right)$ and the response $(Y)$, and the coefficients of the regression model were calculated using the least squares technique [29]. The regression equation is given as

$$
\begin{aligned}
& Y=-567+17.51 X_{1}+10.00 X_{2}+7.96 X_{3}-0.2455 X_{1}{ }^{2}-0.0245 X_{2}{ }^{2}-0.0600 X_{3}{ }^{2}- \\
& 0.0419 X_{1} X_{2}+0.0403 X_{1} X_{3}-0.0132 X_{2} X_{3}
\end{aligned}
$$

The high concentration difference between the TP and solvent mixture at the beginning of the extraction resulted in a rapid increase in the lycopene yield due to the enhanced mass transfer. As the extraction time passes the concentration difference decreases resulting in a decrease in the rate of extraction and the yield becomes nearly constant or decreases depending on the parameters investigated.

The effects of the ultrasonic power, liquid/solid ratio, and extraction time on the lycopene yield using UAE are given in Figure 4 as the three-dimensional response surface plots. In the plots two factors varied in the selected range by keeping the remaining constant at its center point. Although the ultrasonic systems generate heat and mechanical effect due to cavitation, the temperature was kept almost constant at $20 \pm 5^{\circ} \mathrm{C}$ in order to only elucidate the mechanical effect of the ultrasonic power in the UAE 
experiments. Increasing the ultrasonic power up to $180 \mathrm{~W}$ with increasing time and liquid/solid ratio positively affected the yield as shown in Figures $4 \mathrm{a}$ and $\mathrm{b}$, respectively. The increase in the yield is due to the disruption of cell walls with the cavitation micro bubbles collapsed violently, causing the enhancement of the lycopene diffusion from the cell to the solvent medium [4]. When the ultrasonic power was greater than $180 \mathrm{~W}$, the yield started to decrease slightly. The excessive number and size of the bubbles at high ultrasonic power may be too big to collapse which may result in the reduction of cavitation effect or may restrain the transmission of the ultrasonic waves from the probe to the cell wall $[4,22]$. However, when the ultrasonic power increased excessively, the heat produced by the ultrasound cannot be removed in short times even the temperature was kept as constant as possible [22, 30]. This unavoidable increase in temperature may result in decomposition of lycopene. Additionally, the hydroxyl radicals which are produced by the chemical effect of the ultrasonic waves in the extracts and in the presence of the water molecules resulted in the degradation of lycopene.

An increase in the liquid/solid ratio up to 56:1 caused a significant increase in the lycopene yield with the increase in both ultrasonic power and time (Figures $4 \mathrm{~b}$ and $\mathrm{c}$ ) due to the great concentration difference resulting in a high mass transfer rate and acceleration of lycopene diffusion into the liquid. Above this ratio, no significant change in the yield was observed. This phenomenon can be considered as the equilibrium reached in terms of mass transfer between the solid and the liquid [2,22].

Increase in the extraction time increases the lycopene yield up to $23 \mathrm{~min}$, whereas, the yield decreases beyond 23 min with an increase in both the ultrasonic power and liquid/solid ratio as shown in Figures $4 \mathrm{a}$ and c, respectively. The result is in agreement with literature regarding the extraction of lycopene from different sources by UAE: the yield of the lycopene reaches to a maximum with an increase in extraction time and then decreases with extended extraction time due to the degradation of lycopene [2, 4, 22].

An ANOVA analysis was performed in order to determine the significance of each parameter individually and their interaction effects on the yield. The ANOVA analysis given in Table 4 indicated that the most effective parameters on the lycopene yield are the extraction time and liquid/solid ratio $(\mathrm{P}<0.05)$, whereas, the changes in ultrasonic power between 150 and $200 \mathrm{~W}$ was slightly effective.

The RSM predicted the optimum parameters as $166 \mathrm{~W}, 56: 1$ (liquid/solid ratio), and 26 min for UAE by considering the maximum yield as the response.

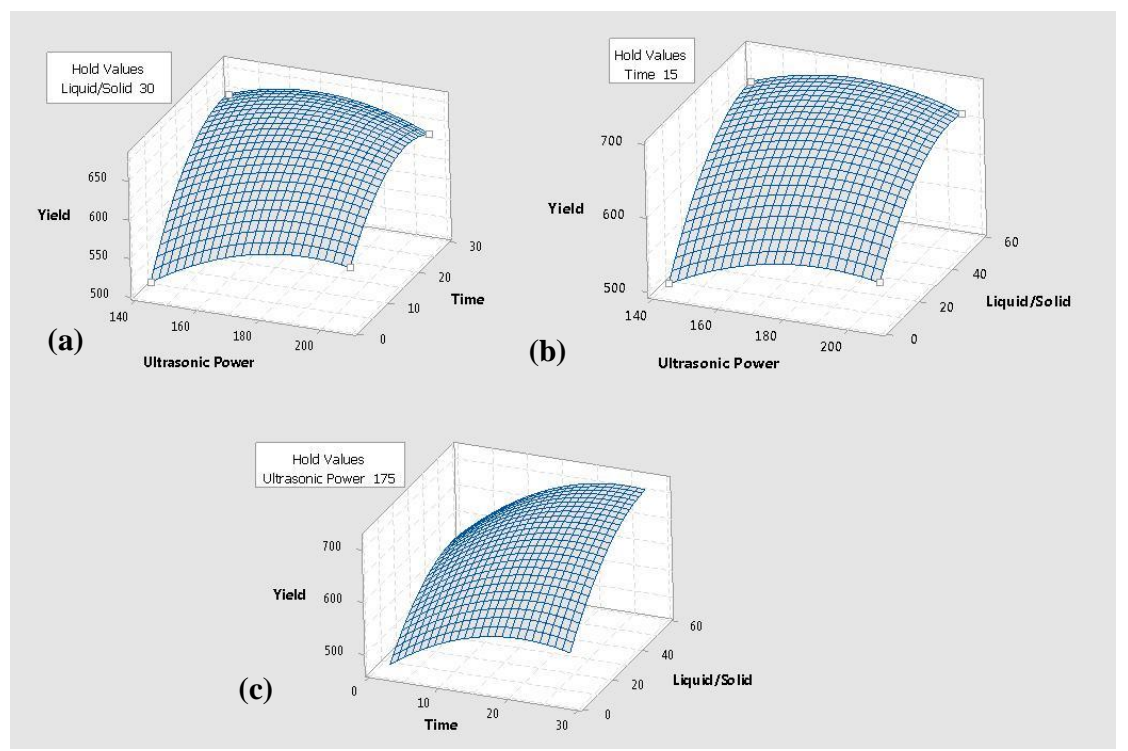

Figure 4. Response surface graph for the combined effect of a. ultrasonic power and extraction time (liquid/solid ratio $=30: 1$ $(\mathrm{v} / \mathrm{w})$ ), b. ultrasonic power and liquid/solid ratio (extraction time $=15 \mathrm{~min}$ ), and c. extraction time and liquid/solid ratio (ultrasonic power $=175 \mathrm{~W}$ ) in UAE. 
Üstündaş et al. / Anadolu Univ. J. of Sci. and Technology A-Appl. Sci. and Eng. 19 (2) - 2018

Table 4. ANOVA of the response for UAE

\begin{tabular}{|c|c|c|c|c|c|}
\hline Term & Degrees of freedom & Sum of squares & Mean square & $F$ value & $P$ value \\
\hline Extraction time, $X_{1}$ & 1 & 18,355 & 18,355 & 46.01 & $<0.001^{*}$ \\
\hline Ultrasonic power, $X_{2}$ & 1 & 1,045 & 1,045 & 2.62 & 0.137 \\
\hline Liquid/solid ratio, $X_{3}$ & 1 & 31,742 & 31,742 & 79.57 & $<0.001^{*}$ \\
\hline$X_{1}^{2}$ & 1 & 4,040 & 4,040 & 10.13 & $0.010^{*}$ \\
\hline$X_{2}^{2}$ & 1 & 1,577 & 1,577 & 3.95 & 0.075 \\
\hline$X_{3}^{2}$ & 1 & 3,868 & 3,868 & 9.70 & $0.011^{*}$ \\
\hline$X_{1} X_{2}$ & 1 & 880 & 880 & 2.21 & 0.168 \\
\hline$X_{1} X_{3}$ & 1 & 519 & 519 & 1.30 & 0.280 \\
\hline$X_{2} X_{3}$ & 1 & 351 & 351 & 0.88 & 0.370 \\
\hline Error & 10 & 3,989 & 399 & & \\
\hline Lack of fit & 5 & 2,229 & 446 & 1.27 & 0.401 \\
\hline Pure error & 5 & 1,760 & 352 & & \\
\hline Total & 19 & 71,185 & & & \\
\hline$R^{2}$ & & 0.9440 & & & \\
\hline
\end{tabular}

*Significant effects, $\alpha=0.05$.

\subsection{COSE Method}

The COSE experiments were performed based on the CCD using three factors, $X_{1}$ (extraction time, min), $X_{2}$ (temperature, ${ }^{\circ} \mathrm{C}$ ), and $X_{3}$ (liquid/solid ratio, v/w). The results indicated that the lycopene yield varies from 426 to $975 \mathrm{mg}$ lycopene $/ \mathrm{kg}$ of TP and from 21 to $49 \mathrm{mg}$ lycopene $/ \mathrm{kg}$ of the fresh tomato depending on the parameters investigated. The regression equation for COSE is given as

$$
\begin{aligned}
& Y=-32+16.34 X_{1}+16.10 X_{2}+8.63 X_{3}-0.1318 X_{1}^{2}-0.1494 X_{2}^{2}-0.0906 X_{3}^{2}- \\
& 0.0852 X_{1} X_{2}+0.0119 X_{1} X_{3}+0.0249 X_{2} X_{3}
\end{aligned}
$$

The effects of the temperature, liquid/solid ratio, and extraction time on the lycopene yield are given in the response surface plots in Figure 5. Although, at a constant liquid/solid ratio of 30, increasing the temperature with increasing the extraction time shows a positive effect on the lycopene yield up to $45^{\circ} \mathrm{C}$, after this temperature, in the period of 0 to $32 \mathrm{~min}$, the yield slightly declines (Figure 5a). Extraction temperature is accelerating the molecular thermal motion and also enhancing the solubility and diffusivity of lycopene. On the contrary, exposing the lycopene molecules to high temperature, causes degradation known as the thermolytic effect [18]. Therefore, a further increase in both the temperature and extraction time increases the rate of lycopene degradation (Figures $5 \mathrm{a}$ and $\mathrm{b}$ ).

A positive effect on the yield was observed with the increase in the liquid/solid ratio with respect to the temperature and extraction time (Figures $5 b$ and c) because of the enhanced mass transfer rate due to the high concentration difference as explained in Section 3.1.

A similar trend, as in UAE, was observed for the extraction time. An increase in the extraction time, up to $45 \mathrm{~min}$ increases the lycopene yield with the increasing temperature and liquid/solid ratio (Figures 5a and c). Beyond this extraction time between 45 and $50 \mathrm{~min}$, the rate of extraction starts to decline since equilibrium is reached in the extraction. Prolonging the extraction time resulted in a decrease in the yield which may occur due to the degradation of lycopene [22]. 
Üstündaş et al. / Anadolu Univ. J. of Sci. and Technology A - Appl. Sci. and Eng. 19 (2) - 2018

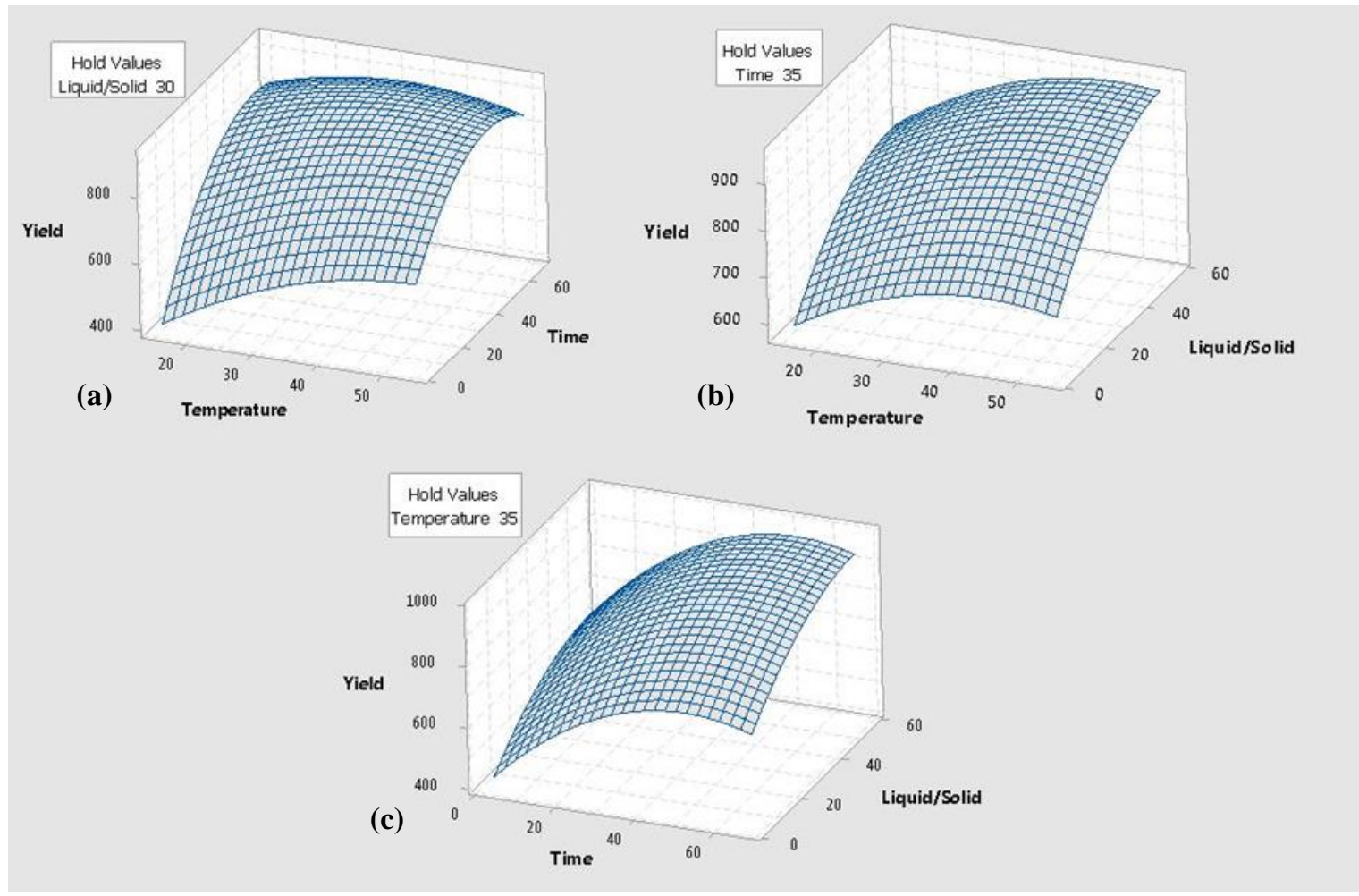

Figure 5. Response surface graph for the combined effect of a. temperature and extraction time (liquid/solid ratio $=30: 1(\mathrm{v} / \mathrm{w})$ ), b. temperature and liquid/solid ratio (extraction time $=35 \mathrm{~min}$ ), and c. extraction time and liquid/solid ratio (temperature $=35^{\circ} \mathrm{C}$ ) in COSE.

The results of the ANOVA analysis given in Table 5 indicates that all of the parameters, extraction time, liquid/solid ratio and extraction temperature, investigated are significant on the yield in COSE. The optimum parameters were found to be as $45^{\circ} \mathrm{C}, 50 \mathrm{~min}$, and 56:1 (liquid/solid ratio) for the maximum lycopene yield.

Verification of the experiments was performed at the optimum conditions predicted for UAE and COSE. The experimental values obtained at the optimum conditions were matched with the predicted values confirming the adequacy of the predicted models. The predicted values of the experiments were satisfactorily achieved within a 95\% confidence interval of the experimental values (Table 6).

Table 5. ANOVA of response for COSE

\begin{tabular}{lccccc}
\hline Term & Degrees of freedom & Sum of squares & Mean square & $F$ value & $P$ value \\
\hline Extraction time, $X_{1}$ & 1 & 143,191 & 143,191 & 96.63 & $<0.001^{*}$ \\
Temperature, $X_{2}$ & 1 & 29,612 & 29,612 & 19.98 & $0.002^{*}$ \\
Liquid/solid ratio, $X_{3}$ & 1 & 91,689 & 91,689 & 61.87 & $<0.001^{*}$ \\
$X_{1}^{2}$ & 1 & 44,649 & 44,649 & 30.13 & $0.001^{*}$ \\
$X_{2}^{2}$ & 1 & 7,434 & 7,434 & 5.02 & 0.055 \\
$X_{3}^{2}$ & 1 & 8,638 & 8,638 & 5.83 & $0.042^{*}$ \\
$X_{1} X_{2}$ & 1 & 8,172 & 8,172 & 5.51 & $0.047^{*}$ \\
$X_{1} X_{3}$ & 1 & 285 & 285 & 0.19 & 0.673 \\
$X_{2} X_{3}$ & 1 & 448 & 448 & 0.30 & 0.598 \\
Error & 8 & 11,855 & 1,482 & & \\
Lack of fit & 5 & 10,133 & 2,027 & 3.53 & 0.164 \\
Pure error & 3 & 1,723 & 574 & - & - \\
Total & 19 & 372,015 & - & - & - \\
$R^{2}$ & - & 0.9243 & - & - & - \\
\hline
\end{tabular}


Üstündaş et al. / Anadolu Univ. J. of Sci. and Technology A-Appl. Sci. and Eng. 19 (2)-2018

Table 6. Comparison of predicted and experimental values for the response at the optimum conditions.*

\begin{tabular}{lcc}
\hline Extraction method & $\begin{array}{c}\text { Experimental value }(\mathrm{mg} \\
\text { lycopene/kg TP) }\end{array}$ & $\begin{array}{c}\text { Predicted value } \\
\text { (mg lycopene/kg TP) }\end{array}$ \\
\hline UAE & 722.321 & 719.981 \\
COSE & 975.833 & 980.972 \\
\hline
\end{tabular}

*The temperature of $45^{\circ} \mathrm{C}, 50 \mathrm{~min}$, and 56:1 (liquid/solid ratio (v/w)) for COSE and ultrasonic power of $166 \mathrm{~W}, 26 \mathrm{~min}$, and 56:1(liquid/solid ratio $(\mathrm{v} / \mathrm{w}))$ for UAE.

For the comparison of the UAE and COSE in terms of the extraction rate, Eqs. (4) and (5) were used to predict the change in the yield for the UAE and COSE, respectively, with respect to the extraction time at a constant temperature of $20^{\circ} \mathrm{C}$ and a liquid/solid ratio of 56:1. As it is seen in Figure 6, although the same lycopene yield was obtained at the end of 40 min extraction time for the UAE and COSE, the extraction rate of UAE is faster than that of COSE. The low mass transfer rate at $20{ }^{\circ} \mathrm{C}$ for COSE may cause the requirement of long extraction time for the same yield achieved in UAE at the same conditions. This result indicated that COSE is more time consuming compared with UAE.

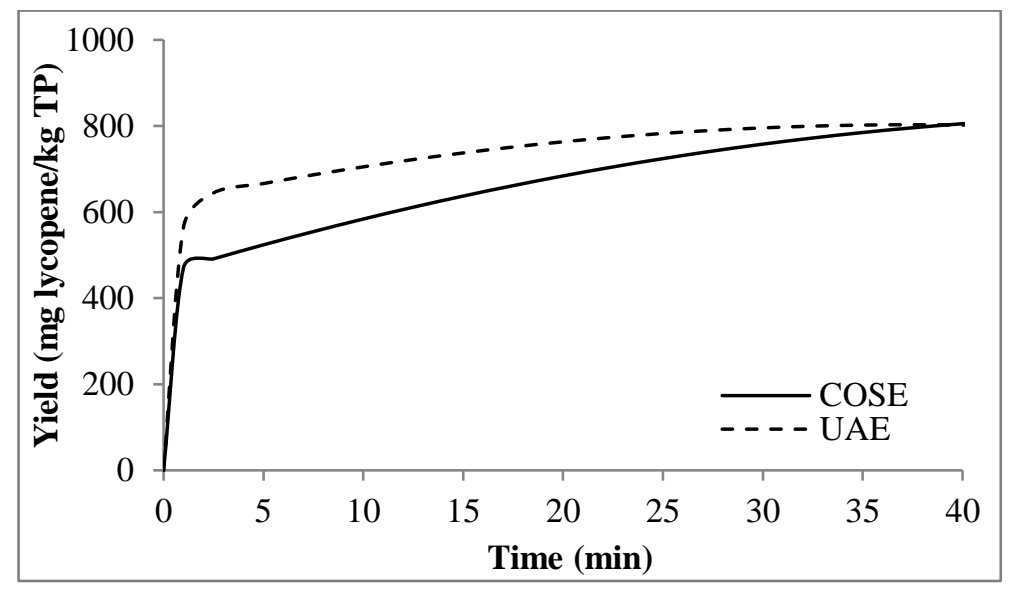

Figure 6. The change in the yield with respect to extraction time (temperature $=20{ }^{\circ} \mathrm{C}$, liquid/solid ratio $=56: 1(\mathrm{v} / \mathrm{w})$ for UAE and COSE; and the ultrasonic power $=166 \mathrm{~W}$ for UAE).

\subsection{Antioxidant Activity of Tomato Powder}

To determine the antioxidant activity of TP, tomato extracts were prepared at the optimum extraction conditions determined for COSE and UAE, separately. The percentage of ABTS inhibitions of the different concentrations of TP extracts and Trolox are shown in Figure 7. The antioxidant capacity of the TP was calculated as the Trolox equivalent antioxidant capacity (TEAC), mg Trolox Equivalent/g TP. The TEAC values and lycopene contents of the extracts are given in Table 7. Increasing the concentration of TP extract increased the lycopene content of the extract solution and thereby increased the inhibition percentage as shown in Figures $7 a$ and $b$. These results were in agreement with literature which indicated that the tomatoes with a high lycopene content show a high antioxidant capacity [31]. The TP extract obtained by UAE exhibited a higher antioxidant capacity than that of the COSE, even though, the lycopene contents of the COSE and UAE are equal. This may be caused by other antioxidant materials beside lycopene being released from the TP with the help of ultrasonic power. 
Üstündaş et al. / Anadolu Univ. J. of Sci. and Technology A - Appl. Sci. and Eng. 19 (2) - 2018
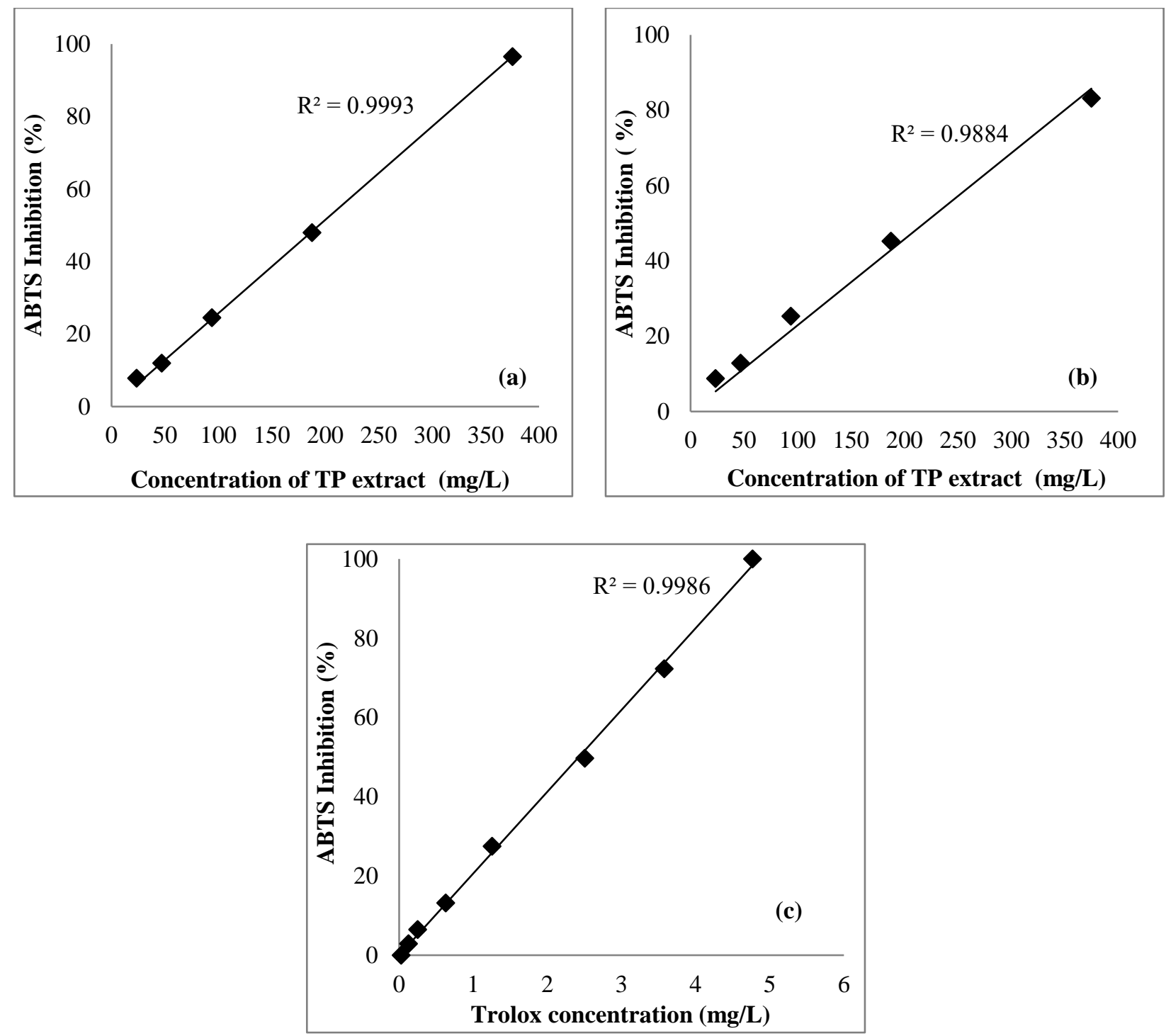

Figure 7. ABTS inhibition of TP extracted using a. UAE (ultrasonic power $=166 \mathrm{~W}$, liquid/solid ratio $=56: 1(\mathrm{v} / \mathrm{w})$, extraction time $=26 \mathrm{~min}$ ), b. $\operatorname{COSE}$ (temperature $=45^{\circ} \mathrm{C}$, liquid $/$ solid ratio $=56: 1(\mathrm{v} / \mathrm{w})$, extraction time $=50 \mathrm{~min}$ ), and c. ABTS inhibition of Trolox as a reference.

Table 7. Antioxidant capacities and lycopene contents of the TP extracted using UAE and COSE.

\begin{tabular}{lcc}
\hline Extraction method & $\begin{array}{l}\text { Antioxidant capacity (TEAC) } \\
(\mathrm{mg} \text { Trolox/g TP) }\end{array}$ & $\begin{array}{l}\text { Lycopene content } \\
\text { (mg lycopene/g TP) }\end{array}$ \\
\hline $\mathrm{UAE}$ & 12.48 & 0.99 \\
$\mathrm{COSE}$ & 11.08 & 0.99 \\
\hline
\end{tabular}

\section{CONCLUSION}

In this study, the effects of the variables (extraction time, liquid/solid ratio, temperature, and ultrasonic power) on the yield of lycopene obtained using the UAE and COSE were investigated. The CCD method was used for the experimental designs of the UAE and COSE. The accuracy of the models defining the relation between the yield and the variables was proved with high correlation constants. 
At the beginning of the UAE and COSE, since the lycopene concentration difference between the solid material and the solvent mixture is high, a sharp increase in the yield of the lycopene was observed. In the UAE, although the extraction time and liquid/solid ratio were found to be significant $(\mathrm{P}<0.05)$, the contribution of ultrasonic power is minor $(\mathrm{P}>0.05)$. In the COSE, the extraction time, liquid/solid ratio, and temperature were found to be significantly effective on the yield of the lycopene $(\mathrm{P}<0.05)$. The parameters affecting the extraction yield of lycopene in the UAE and COSE were optimized in order to obtain a high lycopene yield by preventing lycopene degradation. The RSM predicted the optimum parameters by considering the maximum yield as the response. The optimum parameters are $166 \mathrm{~W}$ (ultrasonic power), 56:1 (liquid/solid ratio), and $26 \mathrm{~min}$ (extraction time) for UAE and $45^{\circ} \mathrm{C}, 50 \mathrm{~min}$, and 56:1 (liquid/solid ratio) for COSE. It was observed that at the same temperature and liquid/solid ratio, the extraction rate of UAE is faster than the COSE. For the same lycopene content, the TP extracts obtained by UAE has more antioxidant capacity than that of COSE.

\section{ACKNOWLEDGMENTS}

This work was supported by The Scientific Research Council of Ege University under 15MUH004. The authors also thank to Prof. Dr. Oğuz BAYRAKTAR for his support and valuable advice on the measurements of antioxidant capacity.

\section{REFERENCES}

[1] Ciriminna R, Fidalgo A, Meneguzzo F, Ilharco LM, Pagliaro M. Lycopene: Emerging Production Methods and Applications of a Valued Carotenoid. ACS Sustainable Chemistry \& Engineering 2016; 4(3):643-650.

[2] Eh AL, Teoh SG. Novel modified ultrasonication technique for the extraction of lycopene from tomatoes. Ultrasonics sonochemistry 2012; 19(1):151-159.

[3] Dóka O, Ficzek G, Luterotti S, Bicanic D, Spruijt R, Buijnsters JG, et al. Simple and Rapid Quantification of Total Carotenoids in Lyophilized Apricots (Prunus armeniaca L.) by Means of Reflectance Colorimetry and Photoacoustic Spectroscopy. Food Technology and Biotechnology 2013; 51(4):453-459.

[4] Xu Y, Pan S. Effects of various factors of ultrasonic treatment on the extraction yield of all-translycopene from red grapefruit (Citrus paradise Macf.). Ultrasonics sonochemistry 2013; 20(4):10261032.

[5] Sadler G, Davis J, Dezman D. Rapid Extraction of Lycopene and P-Carotene from Reconstituted Tomato Paste and Pink Grapefruit Homogenates. Journal of Food Science 1990; 55(5):1460-1461.

[6] Dias MG, Camões MFGFC, Oliveira L. Carotenoids in traditional Portuguese fruits and vegetables. Food Chemistry 2009; 113(3):808-815.

[7] Islam Shishir MR, Taip FS, Aziz NA, Talib RA, Hossain Sarker MS. Optimization of spray drying parameters for pink guava powder using RSM. Food Science and Biotechnology 2016; 25(2):461468.

[8] Li A-N, Li S, Xu D-P, Xu X-R, Chen Y-M, Ling W-H, et al. Optimization of Ultrasound-Assisted Extraction of Lycopene from Papaya Processing Waste by Response Surface Methodology. Food Analytical Methods 2014; 8(5):1207-1214. 
[9] Celli GB, Teixeira AG, Duke TG, Brooks MS-L. Encapsulationof lycopene from watermelon in calcium-alginate microparticles using an optimised inverse-gelation method by response surface methodology. International Journal of Food Science \& Technology 2016; 51(6):1523-1529.

[10] Perkins-Veazie P, Collins JK, Pair SD, Roberts W. Lycopene content differs among red-fleshed watermelon cultivars. Journal of the Science of Food and Agriculture 2001; 81:983-987.

[11] Nobre BP, Gouveia L, Matos PG, Cristino AF, Palavra AF, Mendes RL. Supercritical extraction of lycopene from tomato industrial wastes with ethane. Molecules 2012; 17(7):8397-8407.

[12] Shi J, Le Maguer M, Bryan M. Functional foods-biochemical and processing aspects. USA: CRC Press; 2002. 135-168 p.

[13] Di Mascio P, Devasagayam TPA, Kaiser S, Sies H. Carotenoids, tocopherols and thiols as biological singlet molecular oxygen quenchers. Biochemical Society Transactions 1990; 18:10541056.

[14] Mein JR, Lian F, Wang XD. Biological activity of lycopene metabolites: implications for cancer prevention. Nutrition reviews 2008; 66(12):667-683.

[15] Zhang J, Dhakal I, Stone A, Ning B, Greene G, Lang NP, et al. Plasma carotenoids and prostate cancer: a population-based case-control study in Arkansas. Nutrition and cancer 2007; 59(1):4653.

[16] Ito Y, Kurata M, Suzuki K, Hamajima N, Hishida H, Aoki K. Cardiovascular Disease Mortality and Serum Carotenoid Levels: a Japanese Population-based Follow-up Study. Journal of Epidemiology 2006; 16(4):154-160.

[17] Stahl W, Sies H. Bioactivity and protective effects of natural carotenoids. Biochimica et biophysica acta $2005 ; 1740(2): 101-107$.

[18] Kassama LS, Shi J, Mittal GS. Optimization of supercritical fluid extraction of lycopene from tomato skin with central composite rotatable design model. Separation and Purification Technology 2008; 60(3):278-284.

[19] Zaghdoudi K, Framboisier X, Frochot C, Vanderesse R, Barth D, Kalthoum-Cherif J, et al. Response surface methodology applied to Supercritical Fluid Extraction (SFE) of carotenoids from Persimmon (Diospyros kaki L.). Food Chem 2016; 208:209-219.

[20] Ho KKHY, Ferruzzi MG, Liceaga AM, San Martín-González MF. Microwave-assisted extraction of lycopene in tomato peels: Effect of extraction conditions on all-trans and cis-isomer yields. LWT - Food Science and Technology 2015; 62(1):160-168.

[21] Kumcuoglu S, Yilmaz T, Tavman S. Ultrasound assisted extraction of lycopene from tomato processing wastes. Journal of food science and technology 2014; 51(12):4102-4107.

[22] Liao J, Zheng N, Qu B. An Improved Ultrasonic-Assisted Extraction Method by Optimizing the Ultrasonic Frequency for Enhancing the Extraction Efficiency of Lycopene from Tomatoes. Food Analytical Methods 2016; 9(8):2288-2298.

[23] Abano EE, Ma H, Qu W. Influence of Air Temperature on the Drying Kinetics and Quality of Tomato Slices. Journal of Food Processing \& Technology 2011; 02(05). 
[24] Periago MJ, Rincoä F, Aguera MD, Ros G. Mixture Approach for Optimizing Lycopene Extraction from Tomato and Tomato Products. Journal of Agricultural and Food Chemistry 2004; 52:57965802.

[25] Fish WW, Perkins-Veazie P, Collins JK. A Quantitative Assay for Lycopene That Utilizes Reduced Volumes of Organic Solvents. Journal of Food Composition and Analysis 2002; 15(3):309-317.

[26] Zechmeister L, Lerosen AL, Schroeder WA, Polgar A, Pauling L. Spectral characteristics and configuration of some stereo isomeric carotenoids including prolycopene and pro-gcarotene. Journal of the American Chemical Society 1943; 65:1940-1951.

[27] Kong KW, Ismail A. Lycopene content and lipophilic antioxidant capacity of by-products from Psidium guajava fruits produced during puree production industry. Food and Bioproducts Processing 2011; 89(1):53-61.

[28] Re R, Pellegrini N, Proteggente A, Pannala A, Yang M, Rice-Evans C. Antioxidant Activity Applying an Improved ABTS Radical Cation Decolorization Assay. Free Radical Biology \& Medicine 1999; 6(9/10):1231-1237.

[29] Myers RH, Montgomery DC, Anderson-Cook CM. Response Surface Methodology: Process and Product Optimization Using Designed Experiments. 3rd ed. USA: Wiley; 2009.

[30] Ma YQ, Chen JC, Liu DH, Ye XQ. Simultaneous extraction of phenolic compounds of citrus peel extracts: effect of ultrasound. Ultrasonics sonochemistry 2009; 16(1):57-62.

[31] Cox SE, Stushnoff C, Sampson DA. Relationship of fruit color and light exposure to lycopene content and antioxidant properties of tomato. Canadian Journal of Plant Science 2003; 83(4):913919. 